\title{
Natural History of Squamous Intraepithelial Lesions in Pregnancy and Mode of Delivery
}

\author{
STEFANIE SCHUSTER, ELMAR JOURA and PETRA KOHLBERGER
}

Department of Obstetrics and Gynecology, General Hospital Vienna, Medical University Vienna, Vienna, Austria

\begin{abstract}
Background: Numerous studies have addressed the impact of mode of delivery on the natural history of squamous intraepithelial lesions (SIL) in pregnant women. However, the literature is still contradictory. Patients and Methods: In the course of a retrospective analysis, data of 63 pregnant women with abnormal cervical smears who were referred to our Outpatient Department for pre-invasive lesions of the cervix were analyzed. The study was conducted at the General Hospital in Vienna, Austria, between 2010 and 2015. Data collection included demographics, delivery route and diagnostic results of cervical lesions by cytology, colposcopy, human papilloma virus (HPV) testing, histological report of punch biopsy and, if applicable, cone biopsy. Results: Among 63 women who met the inclusion criteria, 40 (63\%) delivered vaginally and 23 (37\%) underwent caesarean section. Postpartum regression of cervical dysplasia was documented in 15 women delivering vaginally and in 10 who had a caesarean section $(p=0.641)$. Among those women who delivered vaginally, three had progression and in 22 women the lesions persisted postpartum. In the group of women with caesarean section, one had progression and the lesions of 12 women persisted after delivery. No woman had progression to invasive disease. Conclusion: The mode of delivery does not significantly influence the natural history of cervical dysplastic lesions in pregnant women. The numbers of spontaneous regressions to normal cervical cytology during pregnancy were similar in both groups.
\end{abstract}

Human papilloma virus infections are especially common among young women, occurring in about $25 \%$ of the 20 - to 30 -year age group. Moreover, these infections are an important factor contributing to the development of cervical

Correspondence to: Petra Kohlberger MD, Department of Obstetrics and Gynecology, General Hospital Vienna, Medical University Vienna, Waehringer Guertel 18-20, A-1090 Vienna, Austria.E-mail: petra.kohlberger@meduniwien.ac.at

Key Words: Dysplasia, pregnancy, progression, regression, mode of delivery. cancer (1). The incidence of abnormal cervical smears and HPV infections has been reported to be $5-8 \%$ in pregnant as well as non-pregnant women (2-8).

About $30 \%$ of women diagnosed with cervical cancer are in their reproductive years (2). The majority of pregnancies occur between the ages of 18 and 35 years, corresponding to the age range associated with the greatest incidence of HPV infection and following cervical intraepithelial neoplasia (4, 9). This increasing trend may also be attributed to cervical cancer screening being an essential part of prenatal care (10).

Cervical cancer in pregnancy is estimated to have an incidence of 1-10/10,000 pregnancies, depending on the inclusion of carcinoma in situ and postpartum patients $(2,3)$. Approximately $3 \%$ of cervical cancer cases are diagnosed during pregnancy (2). Although cervical cancer in pregnant women is very rare, cervical precancerous lesions have been reported in $5 \%$ of all pregnancies $(5,8,11)$.

Numerous studies showed that $10-70 \%$ of cervical squamous intraepithelial lesion cases in pregnant women regress and sometimes even disappear postpartum $(3,7,8$, 12-15), whereas persistence of CIN is reported in $25-47 \%$ of cases $(3,7,13)$ and progression in $3-30 \%$ of cases $(3,12-14)$.

However, the impact of mode of delivery on the natural history of CIN lesions remains unclear.

\section{Patients and Methods}

Between 2010 and 2015, 63 pregnant women with abnormal PAP smear results who were referred to the Outpatient Department for pre-invasive lesions of the cervix at the General Hospital in Vienna, Austria, were identified through the medical records data repository. Even though there were more pregnant patients with atypical PAP smear results within this period, only 63 had a full data record and were therefore included in this study. One woman presented with invasive cervical cancer during pregnancy at the first visit and was therefore excluded from the study.

The patients had at least one examination, including amongst others cervical cytology, colposcopy, HPV testing and eventually biopsy, prior to delivery and a second examination 6 to 8 weeks postpartum.

The retrospective data review of the patients' medical records revealed age and gestational week at first examination, parity, smoking history during pregnancy, HPV vaccination status, HIV and hepatitis $\mathrm{C}$ status, mode of delivery, antepartum and postpartum 
diagnosis of cervical lesions by cervical cytology, cervical HPV testing and biopsy. Patients characteristics are displayed in Table I.

To determine the impact of the delivery route on the natural development of cervical dysplasia, the patients were analyzed in two groups: (i) vaginally delivering women and (ii) patients with caesarean section as mode of delivery.

The postpartum results were specified into progression, persistence and regression as determined by comparing the antepartum and postpartum cervical smear, categorized as negative for intraepithelial lesion or malignancy (NILM), atypical squamous cells of undetermined significance (ASC-US), low-grade squamous intraepithelial lesion (LSIL) or high-grade squamous intraepithelial lesion (HSIL), and biopsy results, categorized as negative results, CIN1, 2 or 3, of the lesions (according to the terminology utilized at the study period for SIL at our Institution). The regression rates of cervical cytological and histological findings of the two groups were compared using the statistical analysis with IBM SPSS Statistics 24 (IBM Corp., Armonk, NY, USA). Pearson's chi-squared test, unless stated otherwise (level of significance: $\alpha=0.05$ ).

Sociodemographic data were statistically analyzed by Pearson's chi-squared test or by the $t$-test for two independent samples in order to compare the two patient groups. $p$-Values of less than 0.05 were considered statistically significant.

\section{Results}

There were no statistically significant differences between the groups regarding age $(p=0.95)$, gravidity $(p=0.73)$, parity $(p=0.46)$, smoking during pregnancy $(p=0.417)$ and HPV infection status $(p=0.161)$. Two $(9 \%)$ females of the caesarean section cohort were HIV-positive. Three (13\%) women who had a caesarean section and one $(3 \%)$ who delivered vaginally tested positively for hepatitis $\mathrm{C}$. A significantly higher number of HIV $(p=0)$ and hepatitis C $(p=0.001)$ cases in the caesarean section group was found (Table I). Only two (3\%) patients were HPV-negative and only one $(2 \%)$ has been vaccinated against HPV (Table I). Regardless of whether the women underwent cone biopsy or were treated conservatively, no statistically significant difference comparing the cohorts was found ( $p=0.554)$ (Table I). The cytological and histological results of both groups are demonstrated in Table II.

For comparing these rates between the cohorts, those with persistently negative biopsy and not assessable results were excluded, leading to a lower patient number of $25(58.1 \%)$ women who delivered vaginally and 18 (41.9\%) who underwent caesarean section.

Women with LSIL had the highest regression rate (44.4\%) to NILM compared with ASC-US and HSIL antepartum results (Table III). Patients with CIN1 presented the highest regression rate $(40 \%)$ to negative results compared to CIN2 and 3 antepartum results (ASCU-US: Atypical squamous cells of undetermined significance; LSIL: low-grade squamous intraepithelial lesion; HSIL high-grade squamous intraepithelial lesion; AGC: atypical glandular cells; NILM: negative for intraepithelial lesion or malignancy (Table III).
Table I. Patient characteristics.

\begin{tabular}{|c|c|c|}
\hline \multirow[t]{2}{*}{ Characteristic } & \multicolumn{2}{|c|}{ Mode of delivery } \\
\hline & $\begin{array}{c}\text { Vaginal } \\
\text { delivery } \\
(n=40)\end{array}$ & $\begin{array}{c}\text { Caesarean } \\
\text { section } \\
(n=23)\end{array}$ \\
\hline \multicolumn{3}{|l|}{ Age (years) } \\
\hline Mean (SD) & $29( \pm 5)$ & $30( \pm 4)$ \\
\hline \multicolumn{3}{|l|}{ Week of gestation at first } \\
\hline Mean (SD) & $16( \pm 7)$ & $17( \pm 9)$ \\
\hline \multicolumn{3}{|l|}{ Gravidity } \\
\hline Mean (SD) & $2( \pm 1)$ & $2( \pm 1)$ \\
\hline \multicolumn{3}{|l|}{ Parity } \\
\hline Mean (SD) & $2( \pm 1)$ & $2( \pm 1)$ \\
\hline \multicolumn{3}{|l|}{ Nicotine abuse, $\mathrm{n}(\%)$} \\
\hline No & $10(25 \%)$ & $3(13 \%)$ \\
\hline Yes & $12(30 \%)$ & $6(26 \%)$ \\
\hline Not documented & $18(45 \%)$ & $14(61 \%)$ \\
\hline \multicolumn{3}{|l|}{ Hepatitis C status, n (\%) } \\
\hline Negative & $39(97.5 \%)$ & $20(87 \%)$ \\
\hline Positive & $1(2.5 \%)$ & $3(13 \%)$ \\
\hline \multicolumn{3}{|l|}{ HIV status, n (\%) } \\
\hline Negative & $40(100 \%)$ & $21(91 \%)$ \\
\hline Positive & $0(0 \%)$ & $2(9 \%)$ \\
\hline \multicolumn{3}{|l|}{ HPV vaccination status, n (\%) } \\
\hline Not vaccinated & $22(55 \%)$ & $15(65 \%)$ \\
\hline Vaccinated & $1(2.5 \%)$ & $0(0 \%)$ \\
\hline Not documented & $17(42.5 \%)$ & $8(35 \%)$ \\
\hline \multicolumn{3}{|c|}{$\begin{array}{l}\text { Result of HPV testing at first } \\
\text { examination during pregnancy, n (\%) }\end{array}$} \\
\hline Negative & $1(2.5 \%)$ & $1(4 \%)$ \\
\hline High-risk positive & $37(92.5 \%)$ & $21(91 \%)$ \\
\hline Not carried out & $2(5 \%)$ & $1(4 \%)$ \\
\hline \multicolumn{3}{|l|}{ Subsequent procedure, n (\%) } \\
\hline Not documented & $1(2.5 \%)$ & $0(0 \%)$ \\
\hline Cone biopsy & $14(35 \%)$ & $10(43 \%)$ \\
\hline Conservative management & $25(62.5 \%)$ & $13(57 \%)$ \\
\hline
\end{tabular}

There was no statistically significant difference of regression to lower-grade smear results/negativity $(p=0.641)$, nor in persistence $(p=0.828)$ and progression (Fisher's exact test: $p=0.535)$ rates of PAP smear results comparing the two groups (Table I).

No statistically significant difference in regression $(p=0.553)$, persistence $(p=0.405)$ and progression (Fisher's exact test: $p=0.553$ ) rates of biopsy results comparing the two study groups was found (Table IV). No woman had progression to invasive disease.

\section{Discussion}

Reports addressing the effects of the mode of delivery on the clinical course of cervical lesions during pregnancy and postpartum period are limited and contradictory. 
Table II. Distribution and natural history of PAP smear results and histological samples comparing the cohorts.

\begin{tabular}{|c|c|c|}
\hline \multirow[b]{2}{*}{ Comparison of cohorts } & \multicolumn{2}{|c|}{ Mode of delivery, $\mathrm{n}(\%)$} \\
\hline & $\begin{array}{c}\text { Vaginal } \\
\text { delivery } \\
(n=40)\end{array}$ & $\begin{array}{c}\text { Caesarean } \\
\text { section } \\
(n=23)\end{array}$ \\
\hline \multicolumn{3}{|l|}{ Cervical smear results } \\
\hline \multicolumn{3}{|l|}{ Antepartum } \\
\hline ASC-US & $3(7.5 \%)$ & $3(13 \%)$ \\
\hline LSIL & $26(65 \%)$ & $10(43 \%)$ \\
\hline HSIL & $11(27.5 \%)$ & $10(43 \%)$ \\
\hline \multicolumn{3}{|l|}{ Postpartum } \\
\hline NILM & $14(35 \%)$ & $8(35 \%)$ \\
\hline ASC-US & $3(7.5 \%)$ & $1(4 \%)$ \\
\hline LSIL & $11(27.5 \%)$ & $7(30 \%)$ \\
\hline AGC & $0(0 \%)$ & $1(4 \%)$ \\
\hline HSIL & $12(30 \%)$ & $6(26 \%)$ \\
\hline \multicolumn{3}{|l|}{ Natural history } \\
\hline Regression & $15(37.5 \%)$ & $10(43 \%)$ \\
\hline Persistence & $22(55 \%)$ & $12(52 \%)$ \\
\hline Progression & $3(7.5 \%)$ & $1(4 \%)$ \\
\hline \multicolumn{3}{|l|}{ Histological samples } \\
\hline \multicolumn{3}{|l|}{ Antepartum } \\
\hline Negative & $9(22.5 \%)$ & $2(9 \%)$ \\
\hline CIN1 & $5(12.5 \%)$ & $5(22 \%)$ \\
\hline CIN2 & $7(17.5 \%)$ & $6(26 \%)$ \\
\hline CIN3 & $13(32.5 \%)$ & $9(39 \%)$ \\
\hline No biopsy carried out & $6(15 \%)$ & $1(4 \%)$ \\
\hline \multicolumn{3}{|l|}{ Postpartum } \\
\hline Negative & $19(47.5 \%)$ & $6(26 \%)$ \\
\hline CIN1 & $5(12.5 \%)$ & $3(13 \%)$ \\
\hline CIN2 & $4(10 \%)$ & $7(30 \%)$ \\
\hline CIN3 & $7(17.5 \%)$ & $3(13 \%)$ \\
\hline No biopsy carried out & $5(12.5 \%)$ & $2(9 \%)$ \\
\hline Not assessable & $0(0 \%)$ & $2(9 \%)$ \\
\hline \multicolumn{3}{|l|}{ Natural history } \\
\hline Regression & $12(30 \%)$ & $7(30 \%)$ \\
\hline Persistence & $13(32.5 \%)$ & $9(39 \%)$ \\
\hline $\begin{array}{l}\text { Including persistence of } \\
\text { negative result }\end{array}$ & $5(12.5 \%)$ & $1(4 \%)$ \\
\hline Progression & $5(12.5 \%)$ & $3(13 \%)$ \\
\hline Not assessable & $10(25 \%)$ & $4(17 \%)$ \\
\hline
\end{tabular}

ASCU-US: Atypical squamous cells of undetermined significance; LSIL: low-grade squamous intraepithelial lesion; HSIL: high-grade squamous intraepithelial lesion; AGC: atypical glandular cells; NILM: negative for intraepithelial lesion or malignancy; CIN1/2/3: cervical intraepithelial neoplasia grade 1/2/3.

According to our study, the mode of delivery did not significantly influence the natural history of cervical precancerous lesions in the study population. This result correlates with findings of other previously conducted studies (11, 16-19). However, this is in contrast with the results of five other studies $(10,13,20-22)$ which showed higher regression rates in women who delivered vaginally.
Table III. Natural history of cervical smear results of all study participants.

\begin{tabular}{lrcrrr}
\hline Cervical smear & \multicolumn{5}{c}{ Postpartum } \\
\cline { 2 - 6 } results, $n$ & NILM & ASC-US & LSIL & AGC & HSIL \\
\hline Antepartum & & & & & \\
ASC-US (n=6) & 2 & 0 & 3 & 0 & 1 \\
LSIL (n=36) & 16 & 2 & 14 & 1 & 3 \\
HSIL (n=21) & 4 & 2 & 1 & 0 & 14 \\
\hline
\end{tabular}

ASCU-US: Atypical squamous cells of undetermined significance; LSIL: low-grade squamous intraepithelial lesion; HSIL: high-grade squamous intraepithelial lesion; AGC: atypical glandular cells; NILM: negative for intraepithelial lesion or malignancy.

Table IV. Natural history of histological samples of all study participants.

\begin{tabular}{|c|c|c|c|c|c|c|}
\hline \multirow{2}{*}{$\begin{array}{l}\text { Histological } \\
\text { samples, n }\end{array}$} & \multicolumn{6}{|c|}{ Postpartum } \\
\hline & Negative & CIN1 & CIN2 & CIN3 & $\begin{array}{c}\text { Not } \\
\text { carried } \\
\text { out }\end{array}$ & $\begin{array}{c}\text { Not } \\
\text { assess- } \\
\text { able }\end{array}$ \\
\hline \multicolumn{7}{|l|}{ Antepartum } \\
\hline Negative $(n=11)$ & 5 & 3 & 0 & 0 & 3 & 0 \\
\hline CIN1 $(n=10)$ & 4 & 3 & 2 & 0 & 0 & 1 \\
\hline CIN2 (n=13) & 3 & 2 & 5 & 2 & 1 & 0 \\
\hline CIN3 (n=22) & 8 & 0 & 3 & 8 & 2 & 1 \\
\hline Not carried out $(n=7)$ & 5 & 0 & 1 & 0 & 1 & 0 \\
\hline
\end{tabular}

CIN1/2/3: Cervical intraepithelial neoplasia grade $1 / 2 / 3$.

The examination procedure of our study included colposcopy and biopsy for almost all patients, however, Ahdoot et al. merely analyzed cytological data only (21). Furthermore, their degree of cervical dysplasia was unevenly distributed with $45 \%$ patients with HSIL, making the study population less representative for the general population than the findings of our study ( $33 \%$ with antepartum HSIL).

In our study population, the rate of HIV-infected females in the caesarean section group was significantly higher. HIVpositive women undergo caesarean section to protect the newborns from vertical transmission. As these women are more likely to have persistent cervical lesions, this could have served as a confounding factor.

The overall regression rates (cytological regression: $40 \%$, histological regression: $30 \%$ ) in our study population are similar to those reported in previous studies $(3,15,23,24)$. Chung et al. reported a total regression rate of $92.9 \%$ which is much higher than the one found in our study (10). The small population of both studies is taken into account for such different findings. Additionally, sampling errors of 
biopsy and subsequent failed identification of more severe lesions are possible.

The retrospective aspect of the study also probably limits the general applicability of the results. However, it is difficult to conduct a prospective randomized trial as the obstetrical history has to be taken into consideration.

Nonetheless, our study results are hypothesis-generating and compelling. They support the need for a prospective study with a larger population to affirm these significant clinical implications so that pregnant women suffering from CIN can be counselled and treated properly. The diagnosis of CIN during pregnancy can cause anxiety and concern in the expectant mother. Thus, explaining the pathogenesis and treatment options of cervical lesions and the possibility of both delivery modes, vaginally and by caesarean section, is an important tool for patient's compliance.

In conclusion, our retrospective results suggest that the mode of delivery does not significantly influence the natural history of cervical dysplasia in pregnant women. The objective of patient care is to continue the pregnancy and exclude invasive disease.

\section{References}

1 Iftner T, Eberle S, Iftner A, Holz B, Banik N, Quint W and Straube A-N: Prevalence of low-risk and high-risk types of human papillomavirus and other risk factors for HPV infection in Germany within different age groups in women up to 30 years of age: An epidemiological observational study. J Med Virol 82: 1928-1939, 2010.

2 Nguyen C, Montz FJ and Bristow RE: Management of stage I cervical cancer in pregnancy. Obstet Gynecol Surv 55: 633-643, 2000.

3 Palle C, Bangsbøll S and Andreasson B: Cervical intraepithelial neoplasia in pregnancy. Acta Obstet Gynecol Scand 79: 306-310, 2000.

4 Frega A, Scirpa P, Corosu R, Verrico M, Scarciglia ML, Primieri MR, Palazzo A, Iacovelli $\mathrm{R}$ and Moscarini M: Clinical management and follow-up of squamous intraepithelial cervical lesions during pregnancy and postpartum. Anticancer Res 27: 2743-2746, 2007.

5 Campion MJ and Sedlacek TV: Colposcopy in pregnancy. Obstet Gynecol Clin North Am 20: 153-163, 1993.

6 Kaminski PF, Lyon DS, Sorosky JI, Wheelock JB and Podczaski ES: Significance of atypical cervical cytology in pregnancy. Am J Perinatol 9: 340-343, 1992.

7 Vlahos G, Rodolakis A, Diakomanolis E, Stefanidis K, Haidopoulos D, Abela K, Georgountzos V and Michalas S: Conservative management of cervical intraepithelial neoplasia $[\mathrm{CIN}(2-3)]$ in pregnant women. Gynecol Obstet Invest 54: 78-81, 2002.

8 Coppola A, Sorosky J, Casper R, Anderson B and Buller RE: The clinical course of cervical carcinoma in situ diagnosed during pregnancy. Gynecol Oncol 67: 162-165, 1997.

9 Kaplan KJ, Dainty LA, Dolinsky B, Rose GS, Carlson J, McHale $\mathrm{M}$ and Elkas JC: Prognosis and recurrence risk for patients with cervical squamous intraepithelial lesions diagnosed during pregnancy. Cancer 102: 228-232, 2004.
10 Chung SM, Son GH, Nam EJ, Kim YH, Kim YT, Park YW and Kwon JY: Mode of delivery influences the regression of abnormal cervical cytology. Gynecol Obstet Invest 72: 234-238, 2011.

11 Kaneshiro BEK, Acoba JD, Holzman J, Wachi K and Carney ME: Effect of delivery route on natural history of cervical dysplasia. Am J Obstet Gynecol 192: 1452-1454, 2005.

12 Baldauf JJ, Dreyfus M, Ritter J and Philippe E: Colposcopy and directed biopsy reliability during pregnancy: a cohort study. Eur J Obstet Gynecol Reprod Biol 62: 31-36, 1995.

13 Yost NP, Santoso JT, McIntire DD and Iliya FA: Postpartum regression rates of antepartum cervical intraepithelial neoplasia II and III lesions. Obstet Gynecol 93: 359-362, 1999.

14 Douvier S, Filipuzzi L and Sagot P: Management of cervical intra-epithelial neoplasm during pregnancy. Gynecol Obstet Fertil 31: 851-855, 2003.

15 Siddiqui G, Kurzel RB, Lampley EC, Kang HS and Blankstein $\mathrm{J}$ : Cervical dysplasia in pregnancy: progression versus regression post-partum. Int J Fertil Womens Med 46: 278-280, 2001.

16 Murta EFC, de Andrade FCG, Adad SJ and de Souza H: Lowgrade cervical squamous intraepithelial lesion during pregnancy: conservative antepartum management. Eur J Gynaecol Oncol 25: 600-602, 2004.

17 Ackermann S, Gehrsitz C, Mehlhorn G and Beckmann MW: Management and course of histologically verified cervical carcinoma in situ during pregnancy. Acta Obstet Gynecol Scand 85: 1134-1137, 2006.

18 Everson JA, Stika CS and Lurain JR: Postpartum evolution of cervical squamous intraepithelial lesions with respect to the route of delivery. J Low Genit Tract Dis 6: 212-217, 2002.

19 Cubo-Abert M, Centeno-Mediavilla C, Franco-Zabala P, Merced-Vázquez C, Castellví J, García A, Gil-Moreno A and Xercavins J: Risk factors for progression or persistence of squamous intraepithelial lesions diagnosed during pregnancy. $\mathrm{J}$ Low Genit Tract Dis 16: 34-38, 2012.

20 Ueda Y, Enomoto T, Miyatake T, Yoshino K, Fujita M, Miyake $\mathrm{T}$, Fujiwara $\mathrm{K}$, Muraji $\mathrm{M}$, Kanagawa $\mathrm{T}$ and Kimura $\mathrm{T}$ : Postpartum outcome of cervical intraepithelial neoplasia in pregnant women determined by route of delivery. Reprod Sci Thousand Oaks Calif 16: 1034-1039, 2009.

21 Ahdoot D, Van Nostrand KM, Nguyen NJ, Tewari DS, Kurasaki T, DiSaia PJ and Rose GS: The effect of route of delivery on regression of abnormal cervical cytologic findings in the postpartum period. Am J Obstet Gynecol 178: 1116-1120, 1998.

22 Siristatidis C, Vitoratos N, Michailidis E, Syciotis C, Panagiotopoulos N, Kassanos D and Salamalekis E: The role of the mode of delivery in the alteration of intrapartum pathological cervical cytologic findings during the postpartum period. Eur $\mathrm{J}$ Gynaecol Oncol 23: 358-360, 2002.

23 Bansal N, Wright JD, Cohen CJ and Herzog TJ: Natural history of established low grade cervical intraepithelial (CIN 1) lesions. Anticancer Res 28: 1763-1766, 2008.

24 Henes M, Neis F, Rall K, Iftner T, Staebler A, Fehm T and Rothmund R: Abnormal cytology during pregnancy-a retrospective analysis of patients in a dysplasia clinic. Anticancer Res 33: 711-715, 2013.

Received January 8, 2018

Revised January 30, 2018

Accepted February 6, 2018 